\title{
COMPARATIVE IN VITRO DISSOLUTION STUDY ON METFORMIN MARKET PRODUCTS USING DIFFERENT DISSOLUTION APPARATUSES
}

\author{
HANAN M. HASHEM1', AYA R. ABDOU1', NADIA M. MURSI², LAILA H. EMARA1*
}

1Industrial Pharmacy Laboratory, Medical and Pharmaceutical Chemistry Department, Division of Pharmaceutical Industries, National Research Centre, El-Tahrir Street, Dokki, Giza 12622, Egypt, ${ }^{2}$ Department of Pharmaceutics, Faculty of Pharmacy, Cairo University, Cairo, 11562, Egypt

Email: lhhemara@yahoo.com

Received: 27 Jun 2019 Revised and Accepted: 04 Aug 2019

ABSTRACT

Objective: This study was proposed to evaluate and compare the in vitro dissolution profiles of six Metformin Hydrochloride (MH) market products.

Methods: Different dissolution apparatuses (USP apparatus II, IV and beaker method) were used to evaluate the dissolution profiles (in phosphate buffer, pH 6.8) of two immediate release (IR) generic products of Metformin Hydrochloride (MH): Cidophage® 1000 mg (G1, Egyptian market) and Metformin arrow $® 1000 \mathrm{mg}$ (G2, French market) with respect to the reference products named Glucophage ${ }^{8} 850$ mg (R1, Egyptian market and R2, French market). In addition to a generic controlled-release (CR) product; Cidophage Retard® 850 mg (G3) versus the reference product; Glucophage XR® $1000 \mathrm{mg}$ (R3) (both from Egyptian market). Dissolution efficiency (D. E.) and the similarity factor $\left(f_{2}\right)$ were calculated. Weight uniformity, hardness, tablet dimensions and MH content were measured.

Results: Results of the three apparatuses showed that MH IR products studied (reference and generics) did not meet the $75 \%$ USP 30 specifications for $\mathrm{MH}$ dissolved at $30 \mathrm{~min}$. For MH CR products, Glucophage XR® did not fulfill the USP release criteria, while Cidophage Retard $\AA$ did. USP apparatus IV revealed the highest sensitivity and discriminative capability.

Conclusion: Generally, MH IR generics (G1 and G2) might be interchangeable with the innovator product (Glucophageß). However, Cidophage Retard $\AA$ might not be interchangeable with Glucophage XRß.

Keywords: Metformin Hydrochloride, Flow-through cell, Immediate release, Controlled release

(c) 2019 The Authors. Published by Innovare Academic Sciences Pvt Ltd. This is an open-access article under the CC BY license (http://creativecommons.org/licenses/by/4.0/) DOI: http://dx.doi.org/10.22159/ijpps.2019v11i9.34711

\section{INTRODUCTION}

For many years, efforts have been made to minimize the number of in vivo studies required to approve a new molecule or a generic product. One of the approaches currently used is the in vitro (mainly dissolution) tests that act as a tool to predict drug product performance in vivo [1-4]. It is necessary to have precise and reproducible dissolution data resulting from physiochemically and hydrodynamically determined conditions to compare variability and reproducibility for in vitro dissolution data and to manage using such results as a replacement for in vivo bioavailability, bioequivalence testing and in vitro/in vivo correlations (IVIVC) [5].

Dissolution testing is empirical in vitro laboratory performance test that judges how a drug is released from its dosage form efficiently. During drug development, dissolution profiles have been utilized to comprehend the influence of formulation composition on the in vitro release of an active pharmaceutical ingredient (API). It plays as well an important role in the context of science and risk-based process development, validation and evaluation of post-approval formulation changes to drug product quality [6].

Also, after product development, in vitro dissolution is an important test in QC to ensure batch to batch consistency, to establish shelf life during stability studies [7] and to predict in vivo performance (i.e. bioavailability) [2].

Although the Flow through the cell (FTC) became an official USP method since 1995 (USP Apparatus IV) [8], in vitro dissolution studies using this apparatus under different operational conditions and/or features are few in literature [5, 9-17]. Our previous studies using the FTC proved that we should optimize the in vitro dissolution conditions for the finished product or during the preparation of different formulations to achieve accurate and reproducible results and to detect the effect of minor formulation changes upon storage [18].
Metformin, 1,1-dimethyl biguanide, has properties of a strong base $(\mathrm{pKa}, 11.5)(\log \mathrm{P},-1.43)$. Metformin hydrochloride $(\mathrm{MH})$ is a salt of a strong base and a strong acid so it is completely ionized in the physiological $\mathrm{pH}$ [19]. $\mathrm{MH}$ is considered the first-line treatment according to international guidelines for patients with (T2DM). It belongs to a class of drugs known as the biguanides. Bioavailability of $\mathrm{MH}$, when given orally, is $50-60 \%$ and it's the biological half-life of is 1.5-4.5 $\mathrm{h}$ and its main site of absorption is proximal small intestine. Chemically, $\mathrm{MH}$ is freely soluble in water and is classified as class III according to the Biopharmaceutical Classification System (BCS) with high solubility and low permeability [20-23].

Currently, $\mathrm{MH}$ is available in the market as immediate-release (IR) and controlled release (CR) dosage forms. Glucophage ${ }^{\circledR}$ is the innovator product that stands out in terms of quality and efficacy, but because of the high price associated with some branded products, some patients and governments may be biased to go for generic products [24]. Although the active ingredient is synonymous in both generic and brand name drug, evidence proves that there are definite differences in their therapeutic effects [25]. This may be due to differences in rate and extent of absorption [26], excipients and manufacturing processes [27] or the manufacturing variables such as the mixing effect and granulation procedure [7]. Few studies compared the performance of innovator and generic products of $\mathrm{MH}$ in different countries [26, 28-35].

Till now, there are 13 dissolution methods in the U. S. Pharmacopeia [36] for $\mathrm{MH}$ tablets to describe its release profile utilizing either apparatus I or apparatus II at $100 \mathrm{rpm}$ and $1000 \mathrm{ml}$ of phosphate buffer solution ( $\mathrm{pH}$ 6.8) as dissolution medium. Nevertheless, it is still valuable to investigate the in vitro dissolution performance of MH tablets employing USP apparatus IV versus USP apparatus II based on its numerous merits.

Therefore, the focus of this study was to evaluate an in vitro dissolution method for $\mathrm{MH}$, using the flow-through cell apparatus 
(USP apparatus IV) and beaker method (non-official method simulating the USP paddle method) compared to the pharmacopeial USP apparatus II method. This will be carried out on $\mathrm{MH}$ tablet products available in the Egyptian and European market.

\section{MATERIALS AND METHODS}

\section{Materials}

Pure metformin hydrochloride ( $\mathrm{MH}$ ) was kindly donated from Sigma, Cairo, Egypt. MH products evaluated were immediate and controlled release tablets (850 $\mathrm{mg}$ or $1000 \mathrm{mg} \mathrm{MH} /$ tablet) purchased from the Egyptian and European markets. All tests were performed within the products expiration date.

Investigated IR products were: two reference products with the same trade namely: R1-Glucophage ${ }^{\circledR} 850 \mathrm{mg}$ tablets, Merk Serono, France (purchased from a retail pharmacy in Cairo, Egypt) (batch number 110017); R2-Glucophage $₫ 850$ mg tablets, Merk Serono, France (purchased from country representative) (LOT number F5503). Two generic products: G1-Cidophage $\AA 1000 \mathrm{mg}$ tablets, CID, Egypt (batch number 01140534); G2-Metformin arrow® 1000 mg tablets, Arrow Generiques, France (LOT number 1297).

Investigated CR products: reference product; R3-Glucophage XR® 1000 mg tablets, Merk serono, Germany (purchased from a retail pharmacy in Cairo, Egypt) (batch number 171521) and Generic product; G3-Cidophage Retard® $850 \mathrm{mg}$ tablets, CID, Egypt (batch number 03140848).

Sodium hydroxide pellets and Potassium dihydrogen orthophosphate were purchased from ADWIC, Egypt. Methanol (HPLC grade, TEDIA, USA) was used for stock solution preparation. Milli-RO purified water (Millipore Corp., Billerica, MA, USA) was used to prepare the dissolution medium.

\section{Methods}

\section{Analysis of MH}

A standard curve ranging from 0.5 to $10 \mu \mathrm{g} / \mathrm{ml}$ in phosphate buffer ( $\mathrm{pH}$ 6.8) was constructed. A stock solution was prepared by dissolving $5 \mathrm{mg}$ of $\mathrm{MH}$ powder in $50 \mathrm{ml}$ methanol to yield a concentration of $100 \mu \mathrm{g} / \mathrm{ml}$. This solution was serially diluted with phosphate buffer ( $\mathrm{pH} \mathrm{6.8)} \mathrm{to} \mathrm{yield} \mathrm{the} \mathrm{desired} \mathrm{concentration} \mathrm{range.}$ The absorbance of the prepared solutions was measured spectrophotometrically (DU-650 UV-Vis spectrophotometer, Beckman, USA) at predetermined $\lambda_{\max }$ of $231 \mathrm{~nm}$ against the phosphate buffer ( $\mathrm{pH}$ 6.8) as blank. Absorbance was plotted against $\mathrm{MH}$ concentration and the response factor was calculated. Each concentration was analyzed in triplicate and the mean values were calculated. A linear zero-intercept relationship was established, where the slope and regression coefficient were 0.1026 and 1 , respectively. Percent recoveries ranged from $94.02 \%$ to $100.37 \%$, and the average response factor was $9.865 \pm 0.254$.

\section{Tablet characteristics}

\section{Uniformity of weight}

Twenty tablets of each MH product were weighed individually and the weight variation was calculated using Microsoft Excel 2010.

\section{Physical parameters}

Tablet Hardness Tester [MT 503 in 1 Hardness, Diameter and Thickness Tester (Sotax-MT 50 MultiTest 50, Switzerland)] was used for determination of tablet dimensions and hardness of the tested brands (mean of twenty tablets for each product was calculated).

\section{Content uniformity}

Twenty tablets of each product were weighed, ground and the weight equivalent to one tablet was transferred quantitatively into $100 \mathrm{ml}$ volumetric flask. About $70 \mathrm{ml}$ of water was added to each flask and then shaked for 15 min using "temperature-controlled shaking water-bath" (Lab-Line, USA) at $37^{\circ} \mathrm{C}$. The final volume was adjusted with water followed by mixing. The solution was then filtered and appropriate dilutions were done to the filtrate using water. The absorbance was then measured spectrophotometrically (UV-Visible spectrophotometer, Beckman, DU-650, USA) at the predetermined $\lambda_{\max }$ at $231 \mathrm{~nm}$ for $\mathrm{MH}$ [37].

\section{Comparative in vitro dissolution study of MH products}

\section{USP apparatus II (pharmacopeial method)}

For such studies, MH products were examined utilizing USP apparatus II (AT8-Xtend, Sotax, Switzerland) at a rotational speed of $100 \mathrm{rpm}$ at $37.0 \pm 0.5^{\circ} \mathrm{C}$ in $900 \mathrm{ml}$ phosphate buffer (pH 6.8) (fig. 1A). Each dissolution study was done on six tablets. Samples were drawn manually. Each sample was replaced with an equal amount of blank buffer at $37^{\circ} \mathrm{C}$. Samples were then filtered through a syringe filter with a pore size of $0.45 \mu \mathrm{m}$ and a diameter of $25 \mathrm{~mm}$. Dissolution samples were analyzed spectrophotometrically (DU-650 UV-Vis spectrophotometer, Beckman, USA) at predetermined $\lambda_{\max }$ of $231 \mathrm{~nm}$ against the blank.

\section{Flow-through cell apparatus (USP apparatus IV)}

The comparative in vitro dissolution studies of marketed $\mathrm{MH}$ products, were carried out using the closed-loop setup of FTC [USP Apparatus IV, a Dissotest CE-6 equipped with a CY 7-50 piston pump (Sotax, Switzerland)]. Each tablet was placed into the large dissolution cell (22.6 mm diameter). A built-in filtration system with 0.7- $\mu \mathrm{m}$ Whatman glass micro-fiber (GF/F and GF/D) and glass wool were used throughout the study (fig. 1B). The dissolution medium was filtered degassed phosphate buffer $(\mathrm{pH}$ 6.8) maintained at $37.0 \pm 0.5{ }^{\circ} \mathrm{C}$ and pumped at $8 \pm 0.2 \mathrm{ml} / \mathrm{min}$. The dissolution studies were carried out on six tablets. Sample fractions were collected at the following time intervals: 5, 10, 15, 20, 25, 30, 45, 60 and $75 \mathrm{~min}$ for IR products and for appropriate fractions for up to $6 \mathrm{~h}$ for CR products. The fractions were analyzed by UV/spectrophotometric method at $231 \mathrm{~nm}$ against phosphate buffer ( $\mathrm{pH}$ 6.8) as blank.

\section{Beaker method}

For the beaker method, the set up consisted of $1 \mathrm{~L}$ jacketed beakers connected to refrigerated circulator apparatus (julabo circulators F10-VC, Germany). Each beaker was filled with $900 \mathrm{ml}$ phosphate buffer ( $\mathrm{pH}$ 6.8) maintained at $37.0 \pm 0.5{ }^{\circ} \mathrm{C}$. A constant stirring rate was maintained in each beaker using a magnetic stirrer with the magnet kept below a stainless steel mesh (fixed height $=1.5 \mathrm{~cm}$ ) placed at the bottom of each beaker (fig. 1C). Samples fractions were collected at specified time intervals for a total of 75 min for IR products and $6 \mathrm{~h}$ for CR products. The amount dissolved of MH was determined spectrophotometrically as described previously. All experiments were done on six tablets.

\section{Statistical analysis of in vitro dissolution data}

\section{Similarity factor $\left(f_{2}\right)$}

The dissolution profiles of different MH IR and CR market products were compared with the reference product in different apparatuses using similarity factor $\left(f_{2}\right)$ as proposed by Moore and Flanner [38] which is defined as follows (Equation 1):

$$
\mathrm{f}_{2}=50 \log \left\{\left[1+(1 / \mathrm{n}) \sum_{\mathrm{t}=1}^{\mathrm{n}} \mathrm{w}_{\mathrm{t}}\left(\mathrm{R}_{\mathrm{t}}-\mathrm{T}_{\mathrm{t}}\right)^{2}\right]^{-0.5} \times 100\right\} \text { Equation (1) }
$$

Where $R_{t}$ is the percentage of released drug for a reference batch at time point $t, T_{t}$ is the percentage of released drug for the test batch, $n$ is the number of pull points collected during the in vitro release test, $\mathrm{R}_{\mathrm{t}}$ and $\mathrm{T}_{\mathrm{t}}$ are the cumulative percentages release at the selected time point of the two tested formulae. FDA has set a public standard of $f_{2}$ value of 50-100 to indicate similarity between two dissolution profiles [39].

\section{Dissolution efficiency}

Khan and Rhodes [40] used the trapezoidal rule to calculate the area under the dissolution curve at the time $(\mathrm{t})$ to obtain the dissolution efficiency (D. E.) expressed as a percentage of the area of the rectangle described by $100 \%$ dissolution in the same time [41]. (D. E.) is defined as follows: 
D. $E=\frac{\int_{0}^{t} \mathrm{ydt}}{\mathrm{y}_{100} \times \mathrm{t}} \times 100$ Equation (2)

\section{A}
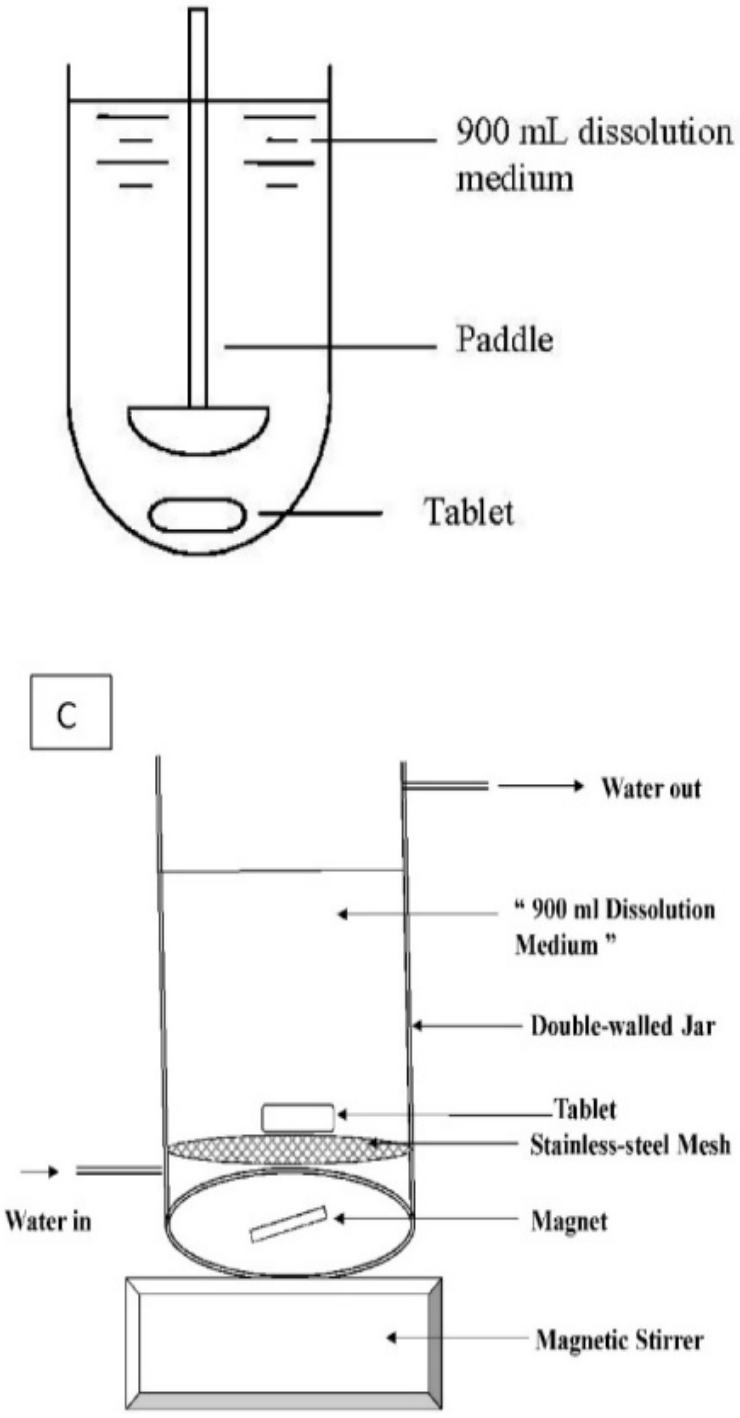

\section{RESULTS AND DISCUSSION}

All MH tablets of the six products under investigation showed acceptable tablet characteristics regarding weight variation, physical parameters and content uniformity, as shown in table 1.

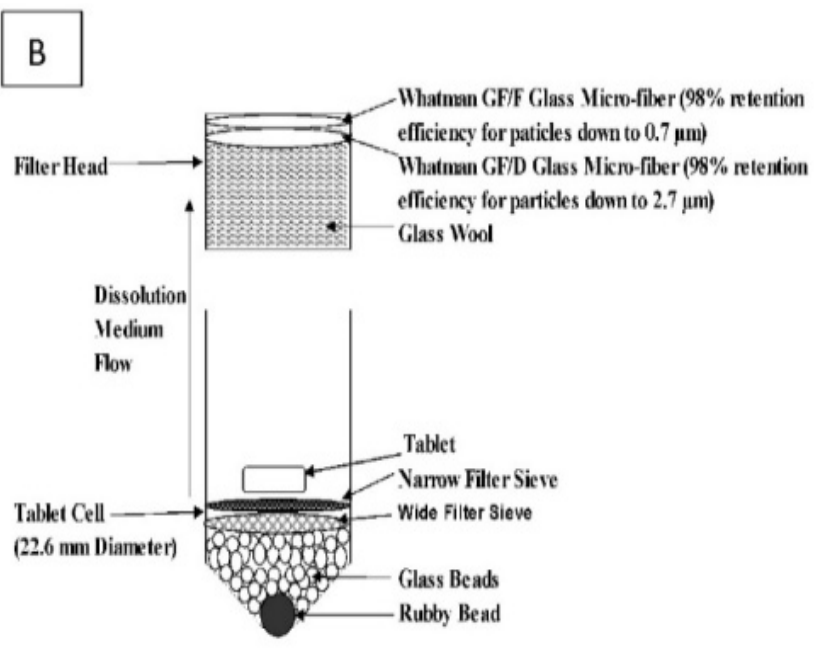

Fig. 1: Schematic diagrams of: (A) USP apparatus II, (B) USP apparatus IV, (C) Beaker method

Table 1: Evaluated physicochemical properties of the six MH market products

\begin{tabular}{|c|c|c|c|c|c|c|c|c|}
\hline Tested product & Appearance & $\begin{array}{l}\text { Average } \\
\text { weight } \\
\text { (mg) }\end{array}$ & $\begin{array}{l}\text { Hardness } \\
\text { (N) }\end{array}$ & $\begin{array}{l}\text { Width } \\
\text { (mm) }\end{array}$ & $\begin{array}{l}\text { Length } \\
(\mathrm{mm})\end{array}$ & $\begin{array}{l}\text { Thickness } \\
\text { (mm) }\end{array}$ & $\begin{array}{l}\text { Diameter } \\
(\mathbf{m m})\end{array}$ & $\begin{array}{l}\text { Drug } \\
\text { Content } \\
(\%)\end{array}$ \\
\hline Glucophage $(850 \mathrm{mg}$, Egyptian market (R1). & Round & $904 \pm 6.6$ & $320 \pm 13.8$ & & & $6.5 \pm 0.01$ & $13.5 \pm 0.02$ & $98.4 \pm 0.5$ \\
\hline Glucophage $® 850 \mathrm{mg}$, French market (R2). & Round & $901 \pm 6.1$ & $281 \pm 4.1$ & & & $6.5 \pm 0.1$ & $13.5 \pm 0.01$ & $99.9 \pm 0.4$ \\
\hline Cidophage ${ }^{\circledR} 1000 \mathrm{mg}$ & Oblong & $1071 \pm 8.2$ & $628 \pm 15.1$ & $9 \pm 0.2$ & $20 \pm 0.1$ & $6.32 \pm 0.2$ & & $98.6 \pm 1$ \\
\hline Metformin arrow® $1000 \mathrm{mg}(\mathrm{G} 2)$. & Oblong & $1108 \pm 3.6$ & $443 \pm 17.6$ & $8.7 \pm 0.01$ & $21.9 \pm 0.2$ & $7.3 \pm 0.01$ & & $95.4 \pm 0.6$ \\
\hline Glucophage XR® 1000 mg (R3). & Oblong & $1441 \pm 8.8$ & $141 \pm 3.7$ & $10.6 \pm 0.1$ & $22.12 \pm 0.01$ & $8.2 \pm 0.1$ & & $95 \pm 0.4$ \\
\hline Cidophage Retard $® 850 \mathrm{mg}(\mathrm{G} 3)$. & Round & $899 \pm 7.8$ & $182 \pm 16.8$ & & & $6.4 \pm 0.02$ & $13.4 \pm 0.01$ & $95.3 \pm 2$ \\
\hline
\end{tabular}

${ }^{*}$ P. C: Product Code, L. N: Lot Number, ${ }^{* *}$ All values expressed as mean \pm SD, where $\mathrm{n}=20$ 

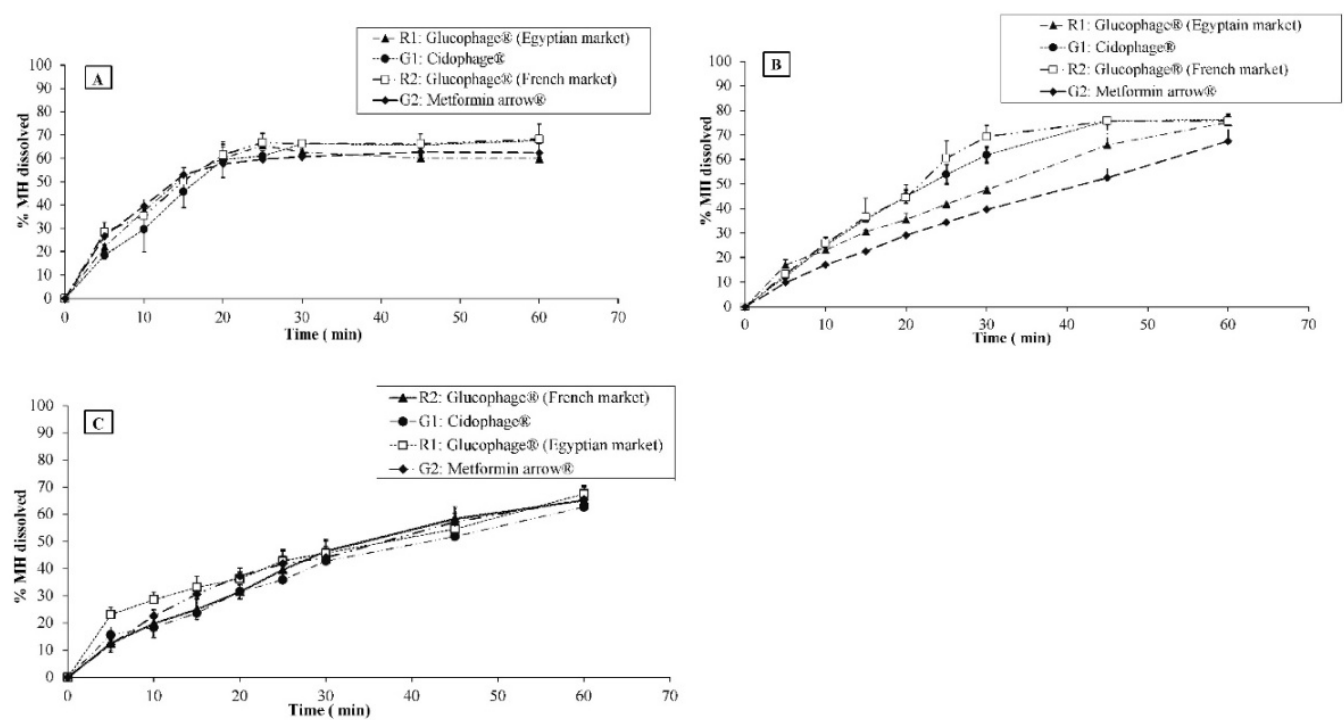

Fig. 2: Dissolution profiles of four MH IR products obtained using: (A) USP apparatus II, (B) USP apparatus IV, and (C) Beaker method $($ mean $\pm S D, n=3$ )

\section{Comparative in vitro dissolution study of MH IR products}

The results of the dissolution experiments carried out in USP apparatuses II, IV and the beaker are presented in (fig. 2: A-C). In the case of USP apparatus II and beaker method, the dissolution behavior of generic products G1 and G2 compared with reference products R1 and R2 were almost identical. On the other hand, dissolution differences were detected upon applying USP Apparatus IV.
The calculated $f_{2}$ values are presented in fig. 3 to compare $\mathrm{MH}$ dissolution profiles of R2, G1 and G2 versus R1: Glucophage ${ }^{\circledR} 850$ mg (Egyptian market). D. E. was also calculated, table 2 lists the corresponding results obtained for the difference of the mean D. E. (D. D. E.) and the difference in confidence intervals (D. C. I.). If the differences of the mean D. E. and the $95 \%$ C. I. are within limits $( \pm 10 \%)$, it can be concluded that the dissolution profiles of the reference and test are equivalent [41].

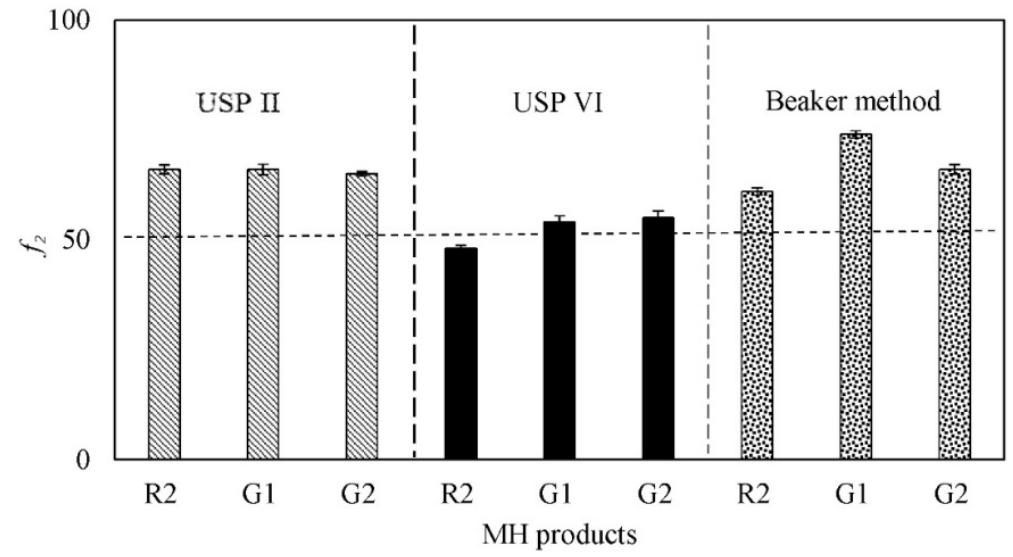

Fig. 3: Comparison between dissolution profiles of different MH IR market products (R2, G1, G2) versus R1 (Glucophage $($ ) expressed by the similarity factor $" f_{2}$ ", utilizing different apparatuses (mean $\pm S D, n=3$ )

\section{USP apparatus II}

The dissolution profiles of R2, G1 and G2 were compared to that of the innovator product R1. It was found that the two parameters of D. E. (D. D. E. and D. C. I.) were accepted for R2: Glucophage® $850 \mathrm{mg}$ (French market), but for the generics Cidophage ${ }^{8}$ (G1) and Metformin arrow ${ }^{\circledR}(G 2)$, D. C. I. was out of range. Thereby, the two products named Glucophage ${ }^{\circledR}$ (R1 and R2) had a similar dissolution profile in terms of D. C. I., D. D. E. (table 2) and $f_{2}$ (fig. 3), while G1 and G2 declared dissimilar dissolution profiles when compared to R1 only in terms of D. C. I. Meanwhile, they all revealed similar dissolution profiles in terms of $f_{2}$ (fig. 3) and D. D. E (table 2). The $\mathrm{Q}_{30}$ $\min$ values were $66.3 \%, 62.7 \%, 66.2 \%$ and $58.7 \%$ for R1, R2, G1, and G2, respectively. Thus, we can conclude that USP apparatus II could hardly detect differences in dissolution profiles of the tested MH IR products.

Table 2: Mean dissolution efficiencies (D. E.) with 95\% confidence intervals (C. I.) calculated from in vitro release data of MH IR tablets

\begin{tabular}{|c|c|c|c|c|c|}
\hline Apparatus & Tested product & Product code & Mean D. E. (\%) with C. I. & D. D. E. & D. C. I. \\
\hline \multirow[t]{3}{*}{ USP II } & Glucophage $囚 850 \mathrm{mg}$, Egyptian market & R1 & $54.65(50.84,58.46)$ & 0 & 0 \\
\hline & Glucophage $® 850 \mathrm{mg}$, French market & R2 & $58.85(54.21,63.48)$ & -4.2 & 4.25 \\
\hline & Cidophage $® 1000 \mathrm{mg}$ & G1 & $55.09(48.72,61.45)$ & -0.44 & 9.74 \\
\hline
\end{tabular}




\begin{tabular}{|c|c|c|c|c|c|}
\hline & Metformin arrow® $1000 \mathrm{mg}$ & G2 & $55.84(51.33,60.35)$ & -1.19 & 7.13 \\
\hline \multirow[t]{4}{*}{ USP IV } & Glucophage $₫ 850$ mg, Egyptian market & $\mathrm{R} 1$ & $51.76(45,65.52)$ & 0 & 0 \\
\hline & Glucophage® 850 mg, French market & $\mathrm{R} 2$ & $57.62(49.22,66.02)$ & -5.86 & 16.3 \\
\hline & Cidophage $₫ 1000 \mathrm{mg}$ & G1 & $57.86(54.73,60.99)$ & -6.1 & 10.79 \\
\hline & Metformin arrow® $1000 \mathrm{mg}$ & G2 & $44(17.66,70.39)$ & 7.76 & 47.86 \\
\hline \multirow[t]{4}{*}{ Beaker method } & Glucophage® 850 mg, Egyptian market & R1 & $46.47(40.56,52.38)$ & 0 & 0 \\
\hline & Glucophage $₫ 850 \mathrm{mg}$, French market & $\mathrm{R} 2$ & $48.74(41.63,55.85)$ & -2.27 & 10.75 \\
\hline & Cidophage $₫ 1000 \mathrm{mg}$ & G1 & $43.92(43.75,44.10)$ & 2.55 & 8.63 \\
\hline & Metformin arrow $® 1000 \mathrm{mg}$ & G2 & $49.56(43.65,55.47)$ & -3.09 & 8.73 \\
\hline
\end{tabular}

*D. E.: Dissolution Efficiency, C. I.: Confidence Intervals, D. D. E.: Difference of the mean D. E. between the innovator and the tested product, D. C. I.: Difference in confidence intervals and is calculated by considering the maximum possible mean D. E. value of Innovator and minimum possible mean D. E. value of other products (mean $\pm S D, n=3$ ).

Other researchers studied the commercially available MH IR products using USP apparatus II. Olusola et al. [28] compared the dissolution rate of eight commercially available $\mathrm{MH}$ tablets in Nigeria and found that only four brands could be considered as biopharmaceutically and chemically equivalent. Sougi et al. [34] conducted a study for evaluation of fifteen MH IR commercial brands in Ghana and concluded that not all the commercial brands of $\mathrm{MH}$ tablets had similar dissolution profiles as the innovator depending on the $f_{2}$ analysis. Previously, a study done by Hamdan and Jaber [42] on five brands of MH in Jordanian market declared that four out of five brands were not equivalent to innovator brand except for one that is equivalent to an innovator in terms of $f_{2}$ analysis of the dissolution profiles. Moreover, another study was done on five IR brands of MH in the Saudian market, which also revealed that all the brands, except one, were non-equivalent to innovator Glucophage product [33].

\section{USP apparatus IV}

Dissolution performance of MH IR products in USP apparatus IV is illustrated in fig. 2(B). The $\mathrm{Q}_{30}$ min results were $47.6 \%, 69.3 \%, 61.8 \%$ and $40 \%$ for R1, R2, G1, and G2, respectively. Fig. 2 clarified that USP apparatus IV was the dissolution apparatus that revealed the highest sensitivity and discriminative capability in differentiating between the dissolution behavior of MH products than USP apparatus II and beaker method. Similar observations were reported by Hurtado y de la Peña et al. [43] who highlighted by statistical analysis the discriminative capability of USP apparatus IV versus USP apparatus II in differentiating the release characteristics of tested albendazole products.

Fig. 3 shows a comparison between dissolution profiles of different MH IR market products (R2, G1, G2) versus R1 (Glucophage ${ }^{\circledR}$ ) expressed by similarity factor " $f_{2}$ ", utilizing different apparatuses while table 2 shows the mean dissolution efficiencies (D. E.) with $95 \%$ confidence intervals (C. I.) calculated from in vitro release data of MH IR tablets. According to fig. 3 and table 2, USP apparatus IV revealed that the two innovator products (R1 and R2), named Glucophage, (from Egyptian and French markets) have dissimilar dissolution profiles in terms of $f_{2}(48)$, D. D. E. $(-5.86)$ and D. C. I. $(16.3 \pm 10 \%)$.

The dissolution profiles of the two generic MH IR products (G1, G2) were compared with the innovator R1 using $f_{2}$ (fig. 3 ) and D. E. (table 2). $f_{2}$ values were 54 and 55 for G1 and G2, respectively indicating similar dissolution profiles (fig. 3). However, upon comparing the dissolution efficiency of these two generic MH products with respect to the innovator R1, it was found that D. D. E values $(-6.1$ and 7.76 for G1 and G2, respectively) and D. C. I. values (10.79 and 47.86 for G1and G2, respectively) were out of range (table 2) which indicated dissolution dissimilarity between G1 and G2 versus innovator R1 under these operational conditions.

In case of R1 and R2, our results that show dissolution dissimilarity is in consistence with Stuart et al. [31] who assumed that the two $\mathrm{MH}$ innovator products having similar trade name (Glucophage), but came from different manufacturers, were statistically different regarding their dissolution profiles. Likewise, Crison et al. [44] stated that MH IR tablets obtained from different markets showed diverse drug release profiles. Moreover, in a previous study done using USP apparatus IV [12], the authors concluded that two tested reference products of diclofenac sodium tablets (Voltaren $100 \mathrm{mg}$ ) manufactured in different manufacturing sites (Novartis-Egypt, Novartis-Switzerland), displayed notable differences in the release rate of diclofenac sodium. In this respect, the two products might give different in vivo data [45].

The perceived variations between results obtained from USP apparatus II and IV can be explained due to differences in the hydrodynamic conditions that characterize this system. Medina et al. [46] reported a comparative in vitro dissolution study of carbamazepine immediate-release products using the USP apparatus II method and the flow-through cell apparatus and concluded that all products showed a slower dissolution rate in USP apparatus IV than the one found with the USP paddle method. Langenbucher et al. [48] clarified that kind of behavior to be related to the hydrodynamic conditions that illustrate the flow-through cell apparatus, where no agitation mechanisms exist so the dosage form is exposed to a uniform flow, like the surroundings of the GIT, producing different dissolution pattern.

The hypothesis of the effect of variable hydrodynamics on drug dissolution came to be verified by McCarthy et al. [49] depending on a high-performance computing software system to simulate the USP dissolution apparatus II (paddle apparatus) to characterize the fluid hydrodynamics in the method. Similarly, Computational analysis was used to examine the hydrodynamic environment within USP apparatus II at common operating conditions by Kukura et al. Their results showed that the uneven distribution of hydrodynamic forces in USP apparatus II is a direct cause of dissolution testing variability [50].

\section{Beaker method}

The dissolution profiles of the four MH IR tested products obtained using the beaker method are plotted in fig. 2(C). R1, R2, and G1 apparently showed slower dissolution rates in beaker method than in other apparatuses in terms of Q30 min; the values were $46.7 \%$, $45.8 \%, 42.8 \%$ for R1, R2 and G1, respectively. But for G2, Q30 min (44\%) was close to that of USP apparatus IV (40\%). In terms of f2 (fig. 3) and D.D.E. (table 2), R2 and the generic products (G1 \& G2) had similar dissolution profiles with respect to innovator product R1, opposing D.C.I. values which revealed dissimilar dissolution profiles (table 2).

From the previous results, it was found that the dissolution profiles of the two investigated MH IR innovator products (R1 and R2) were similar when USP apparatus II $\left(f_{2}=66\right)$ and beaker method $\left(f_{2}=61\right)$ were used, while opposite results were found with USP apparatus IV $\left(f_{2}=48\right)$ (fig. 3). Nevertheless, Wong and Ngo [32] reported that even if multiple generic MH IR tablets had different dissolution profiles in vitro, the in vivo performance might not likely be diverted to a clinically significant extent. The previous conclusion was in complete accordance with Oyetunde et al. [29] who discussed in their study that even if the dissolution performance of BSC class III drug products were found to be relatively slow, they may still have similar in vivo absorption.

Our study revealed that the reported MH pharmacopeial dissolution test was not discriminating enough, to show minor differences between dissolution patterns of different generics (fig. 3). On the other hand, USP apparatus IV was more beneficial in the 
development of a much more discriminating dissolution method than the pharmacopeial method, similar observations were stated by Medina et al. [46] who studied in vitro dissolution profiles of carbamazepine IR generic tablet products using different dissolution apparatuses (II and IV). In a recent study, similar observation regarding USP apparatus IV and II was noticed for marketed suspensions of carbamazepine [47]. Again this was in accordance with the work done by Gite et al. [51] on atorvastatin using USP apparatus I and IV.

According to USP specifications, the percent of MH dissolved from IR tablet products should not be less than $75 \%$ of the labeled amount of $\mathrm{MH}$ in $30 \mathrm{~min}\left(\mathrm{Q}_{30 \mathrm{~min}}\right)$. It is noticeable from $\mathrm{Q}_{30 \mathrm{~min}}$ values listed above that no matter which apparatus was employed, none of MH IR products met the requirements of the USP pharmacopeia [37]. Likewise, other researchers faced such out of limits results. For example, Hurtado y de la Peña et al. [43] reported that for different marketed albendazole products, only the reference product and one of the generic products studied met the USP specifications. Moreover, Emara et al. [18] presented two commercial products of gliclazide that failed to meet the requirements described by the British Pharmacopoeia.

\section{Comparative in vitro release study of MH CR products}

Dissolution profiles of the two MH CR products studied, R3 and G3, obtained using USP apparatus II, USP apparatus IV and beaker
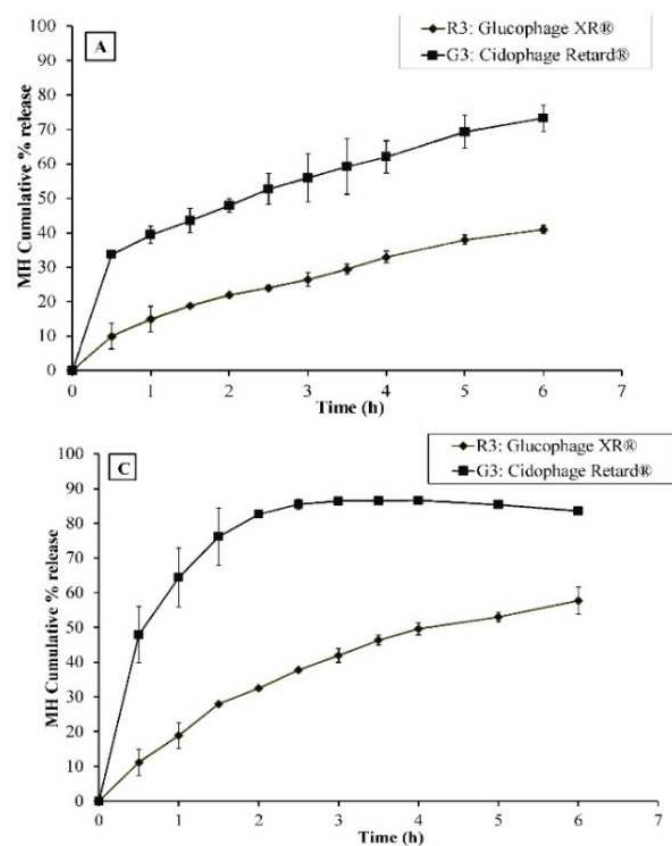

method are shown in fig. 4 (A-C). Regarding MH CR products, the amount of drug released in $6 \mathrm{~h}\left(\mathrm{Q}_{6 \mathrm{~h}}\right)$ according to USP specifications for $\mathrm{MH}$ tablet assay should be between $65-85 \%$ of the labeled amount of $\mathrm{MH}$ [36]. The dissolution results of $\mathrm{MH}$ CR commercial products (fig. 4: A-C) revealed that the innovator product R3 (Glucophage XRß) did not meet these USP release criteria. Q6h values for R3 were $40.1 \%, 37.8 \%$ and $57.7 \%$ obtained by USP apparatuses II, IV and beaker method, respectively. On the other hand, the generic product G3 (Cidophage Retard $囚$ ) complied with these specifications.

Fig. 5 displayed a comparison between dissolution profiles of MH CR generic product G3 (Cidophage Retard) versus R3 (Glucophage $\mathrm{XR}$ () expressed by the similarity factor " $f_{2}$ ", utilizing different apparatuses. Meanwhile, table 3 listed the mean dissolution efficiencies (D. E.) with 95\% confidence intervals (C. I.) calculated from in vitro release data of $\mathrm{MH}$ CR tablets. For all studied apparatuses, the dissolution profile of the generic product G3 (Cidophage Retard $®$ ) was dissimilar with the innovator R3 in terms of D. D. E., D. C. I. and $f_{2}$ (table 3 and fig. 5). Thereby, it might not be interchangeable with the reference brand. This variability in $\mathrm{MH}$ release may be due to differences in particle size and/or surface area of $\mathrm{MH}$ particles, uneven distribution of hydrodynamic force [50] or differences in the method of manufacturing, compression force or machinery [52].

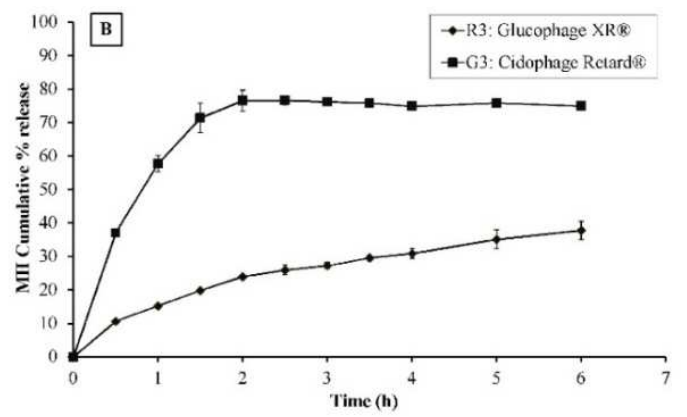

Fig. 4: Dissolution profiles of two MH CR products obtained using: (A) USP apparatus II, (B) USP apparatus IV, and (C) Beaker method $(\mathrm{mean} \pm \mathrm{SD}, \mathrm{n}=3)$

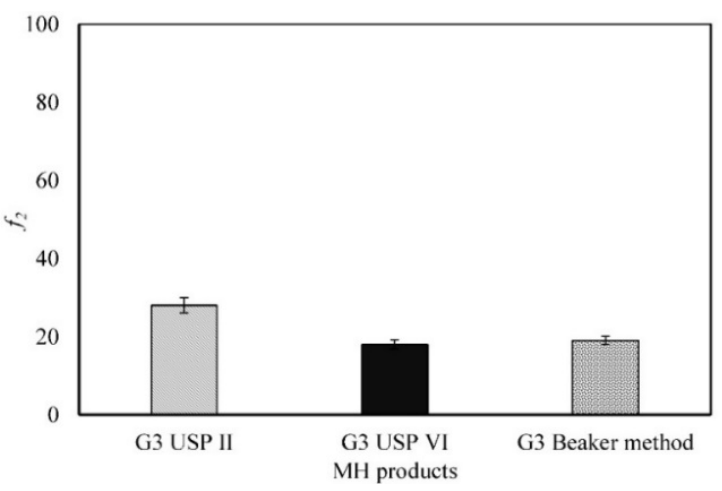

Fig. 5: Comparison between dissolution profiles of G3 generic product (Cidophage Retard) versus R3 (Glucophage XRß) expressed by the similarity factor " $f_{2} "$, utilizing different apparatuses (mean $\pm S D, n=3$ ) 
Table 3: Mean dissolution efficiencies (D. E.) with 95\% confidence intervals (C. I.) calculated from in vitro release data of MH CR tablets

\begin{tabular}{|c|c|c|c|c|c|}
\hline Apparatus & Tested product & Product code & Mean D. E. (\%) with C. I. & D. D.E. & D. C. I. \\
\hline \multirow{2}{*}{ USP 2} & Glucophage XR® $1000 \mathrm{mg}$ & R3 & $27.27(22.92,31.61)$ & 0 & 0 \\
\hline & Cidophage Retard® $850 \mathrm{mg}$ & G3 & $53.04(50.42,55.67)$ & -25.77 & -18.81 \\
\hline \multirow[t]{2}{*}{ USP 4} & Glucophage XR® $1000 \mathrm{mg}$ & R3 & $25.57(14.86,36.28)$ & 0 & 0 \\
\hline & Cidophage Retard® $850 \mathrm{mg}$ & G3 & $67.57(64.27,70.87)$ & -42 & -27.99 \\
\hline \multirow[t]{2}{*}{ Beaker method } & Glucophage XR® $1000 \mathrm{mg}$ & R3 & $37.63(21.55,53.72)$ & 0 & 0 \\
\hline & Cidophage Retard® $850 \mathrm{mg}$ & G3 & $75.45(55.66,95.25)$ & -37.82 & -1.94 \\
\hline
\end{tabular}

*D. E.: Dissolution Efficiency, C. I.: Confidence Intervals, D. D. E.: Difference of the mean D. E. between the innovator and the tested product, D. C. I. Difference in confidence intervals and is calculated by considering the maximum possible mean D. E. value of Innovator and minimum possible mean D. E. value of other products (mean $\pm S D, n=3$ ).

Despite the possible importance of the effect of different excipients on the release profile of $\mathrm{MH}$ tablets under test, it could not be evaluated because only the innovator product R3 (Glucophage XRß) listed the excipients on its pamphlet. In this context, Block et al. and Stuart et al. [31, 53] stated that the difference in dissolution profiles of products could be attributed to the excipients and/or the manufacturing process. Furthermore, Berthelsen et al. [54] reported that excipients might disturb the drug-filter interaction/adsorption in USP apparatus IV, causing differences in dissolution profiles and interfering with the prediction of in vivo data.

Shaw and Krauss [55] informed that the FDA has not publicized safety in generic-to-generic switches, which could possibly cause drug concentration deviations up to $40 \%$. Our present study involving USP apparatus II and IV and beaker method revealed significant differences in the rate of release of MH from Egyptian CR generic product investigated as compared to the innovator product.

Although USP apparatus IV can usually discriminate between different pharmaceutical products, nevertheless, it has some disadvantages as there is always a risk of filter clogging, difficulties in confirming the flow rate during testing, and a necessity for a very large amount of dissolution medium for open system runs [54]. As a result of such possible problems, it might still be better to use the Pharmacopeial method (USP apparatus II).

\section{CONCLUSION}

Data with the flow-through cell apparatus approve that the dissolution method proposed has a greater discriminating ability compared to USP apparatus II and beaker method to assess differences in dissolution profiles of $\mathrm{MH}$ market products. Our results revealed that the same trade name does not consequently indicate that products are pharmaceutically identical. The study showed that the dissolution performance of the investigated $\mathrm{MH}$ market products was questionable, where only the generic CR product succeeded to meet the USP dissolution specifications under the studied test conditions. On the contrary of MH IR products, generic MH CR product showed dissimilar dissolution behavior compared to the innovator product. Accordingly, we recommend that physicians and pharmacists should generally avoid the hypothesis that generic and reference market products are therapeutically equivalent and hence could be interchangeable safely, even when labeled to contain the same drug substance. It is possible to mention that MH products with differences in dissolution performance are candidates to show bioavailability differences.

\section{ACKNOWLEDGMENT}

This work was financially supported by the National Research Centre.

\section{AUTHORS CONTRIBUTIONS}

All authors have contributed equally to this manuscript

\section{CONFLICT OF INTERESTS}

There is no conflict of interest to disclose

\section{REFERENCES}

1. Jantratid E, De Maio V, Ronda E, Mattavelli V, Vertzoni M, Dressman J. Application of bio-relevant dissolution tests to the prediction of in vivo performance of diclofenac sodium from an oral modified-release pellet dosage form. Eur J Pharm Sci 2009;37:434-41.

2. Tsume Y, Igawa N, Drelich AJ, Ruan H, Amidon GE, Amidon GL. The in vivo predictive dissolution for immediate release dosage of donepezil and danazol, BCS class IIc drugs, with the GIS and the USP II with biphasic dissolution apparatus. J Drug Delivery Sci Technol 2019. https://doi.org/10.1016/j.jddst.2019.01.035

3. Emara LH, El-Ashmawy AA, Taha N. Stability and bioavailability of diltiazem/polyethylene oxide matrix tablets. Pharm Dev Technol 2018;23:1057-66.

4. Emara LH, Emam MF, Taha NF, Raslan HM, El-Ashmawy A. A simple and sensitive HPLC/UV method for determination of meloxicam in human plasma for bioavailability and bioequivalence studies. J Appl Pharm Sci 2016;6:012-9.

5. Emara LH, Emam MF, Taha NF, El-ashmawy AA, Mursi NM. In vitro dissolution study of meloxicam immediate-release products using flow-through cell (USP apparatus 4) under different operational conditions. Int J Pharm Pharm Sci 2014b;6:254-60.

6. Zaborenko N, Shi Z, Corredor CC, Smith Goettler BM, Zhang L, Hermans A, et al. First-principles and empirical approaches to predicting in vitro dissolution for pharmaceutical formulation and process development and for product release testing. AAPS J 2019;21:32.

7. Maggio RM, Castellano PM, Kaufman TS. A new principal component analysis-based approach for testing "similarity" of drug dissolution profiles. Eur J Pharm Sci 2008;34:66-77.

8. Wähling C, Schröter C, Hanefeld A. Flow-through cell method and IVIVR for poorly soluble drugs. Dissolution Technol 2011;18:15-25.

9. Emara L, El-Menshawi B, Estefan M. In vitro-in vivo correlation and comparative bioavailability of vincamine in prolongedrelease preparations. Drug Dev Ind Pharm 2000;26:243-51.

10. Emara LH, Abdelfattah FM, Taha NF, El-Ashmawy AA, Mursi NM. In vitro evaluation of ibuprofen hot-melt extruded pellets employing different designs of the flow-through cell. Int J Pharm Pharm Sci 2014a;6:192-7.

11. Emara LH, Abdou AR, El-Ashmawy AA, Badr RM, Taha NF, Mursi NM. In vitro release evaluation of gastroretentive amoxicillin floating tablets employing a specific design of the flow-through cell. Dissolution Technol 2013;20:27-35.

12. Emara LH, Taha NF, Mursi NM. Investigation of the effect of different flow-through cell designs on the release of diclofenac sodium SR tablets. Dissolution Technol 2009;16:23-31.

13. Fotaki N, Reppas C. The flow-through cell methodology in the evaluation of intraluminal drug release characteristics. Dissolution Technol 2005;12:17-21.

14. Krämer J, Stippler E. Experiences with USP apparatus 4 calibration. Dissolution Technol 2005;12:33-9.

15. Beyssac E, Lavigne J. Dissolution study of active pharmaceutical ingredients using the flow-through apparatus USP 4 . Dissolution Technol 2005;12:23-5. 
16. Bhattachar SN, Wesley JA, Fioritto A, Martin PJ, Babu SR. Dissolution testing of a poorly soluble compound using the flow-through cell dissolution apparatus. Int J Pharm 2002;236:135-43.

17. Tang J, Srinivasan S, Yuan W, Ming R, Liu Y, Dai Z, et al. Development of a flow-through USP 4 apparatus drug release assay for the evaluation of amphotericin B liposome. Eur J Pharm Biopharm 2019;134:107-16.

18. Emara LH, Elsayed EW, El-Ashmawy AA, Abdou AR, Morsi NM. The flow-through cell as an in vitro dissolution discriminative tool for evaluation of gliclazide solid dispersions. J Appl Pharm Sci 2017;7:70-7.

19. de Carvalho Mendes T, Simon A, Menezes JCV, Pinto EC, Cabral LM, de Sousa VP. Development of USP apparatus 3 dissolution method with IVIVC for extended-release tablets of metformin hydrochloride and development of a generic formulation. Chem Pharm Bull 2019;16:23-31.

20. Adikwu MU, Yoshikawa Y, Takada K. Pharmacodynamicpharmacokinetic profiles of metformin hydrochloride from a mucoadhesive formulation of a polysaccharide with antidiabetic property in streptozotocin-induced diabetic rat models. Biomaterials 2004;25:3041-8.

21. $\mathrm{Hu} \mathrm{LD}$, Liu $\mathrm{Y}$, Tang $\mathrm{X}$, Zhang $\mathrm{Q}$. Preparation and in vitro/in vivo evaluation of sustained-release metformin hydrochloride pellets. Eur J Pharm Biopharm 2006;64:185-92.

22. Stepensky D, Friedman M, Srour W, Raz I, Hoffman A. Preclinical evaluation of pharmacokinetic-pharmacodynamic rationale for oral CR metformin formulation. J Controlled Release 2001;71:107-15.

23. Frias JP. Fixed-dose combination of ertugliflozin and metformin hydrochloride for the treatment of type 2 diabetes. Expert Rev Endocrinol Metab 2019;14:75-83.

24. Adegbola AJ, Awobusuyi OJ, Adeagbo BA, Oladokun BS, Owolabi AR, Soyinka JO. Bioequivalence study of generic metformin hydrochloride in healthy nigerian volunteers. J Explor Res Pharmacol 2017;2:78-84.

25. Fujii A, Yasui Furukori N, Nakagami T, Niioka T, Saito M, Sato Y, et al. Comparative in vivo bioequivalence and in vitro dissolution of two valproic acid sustained-release formulations. Drug Des Dev Ther 2008;2:139-44.

26. Zakeri Milani P, Nayyeri Maleki P, Ghanbarzadeh S, Nemati M, Valizadeh H. In vitro bioequivalence study of 8 brands of metformin tablets in Iran market. J Appl Pharm Sci 2012;2:194-7.

27. Oner ZG, Polli JE. Authorized generic drugs: an overview. AAPS PharmSciTech 2018;19:2450-8.

28. Olusola AM, Adekoya AI, Olanrewaju OJ. Comparative evaluation of physicochemical properties of some commercially available brands of metformin HCL tablets in lagos, Nigeria. J Appl Pharm Sci 2012;2:41-4.

29. Oyetunde 00, Tayo F, Akinleye MO, Aina BA. In vitro equivalence studies of generic metformin hydrochloride tablets and propranolol hydrochloride tablets under biowaiver conditions in lagos state, Nigeria. Dissolution Technol 2012;51-5.

30. Prithi IJ, Chowdhury SF, Tasneem S. Comparative in vitro dissolution test and other physicochemical parameters of some commercially available metformin $\mathrm{HCl}$ brands in Bangladesh. J Pharm Innov 2018;7:5-8.

31. Stuart AV, Clement Y, Sealy P, Lobenberg R, Montane Jaime L, Maharaj $\mathrm{R}$, et al. Comparing the dissolution profiles of seven metformin formulations in simulated intestinal fluid. Dissolution Technol 2015;22:17-22.

32. Wong SS, Ngo S. Use of in vitro dissolution testing to assess multiple generic metformin tablets. Br J Pharm Res 2018;21:1-9.

33. Afifi SA, Ahmadeen S. A comparative study for evaluation of different brands of metformin hydrochloride $500 \mathrm{mg}$ tablets marketed in Saudi Arabia. Life Sci J 2012;9:4260-6.

34. Sougi A, Ofori Kwakye K, Kuntworbe N, Kipo SL, El Boakye Gyasi M. Evaluation of the physicochemical and in vitro dissolution properties of metformin hydrochloride tablet brands marketed in five cities in ghana. $\mathrm{Br} J$ Pharm Res 2016;1:1-14.
35. Chandrasekaran AR, Jia CY, Theng CS, Muniandy T, Muralidharan S, Dhanaraj SA. In vitro studies and evaluation of metformin marketed tablets-Malaysia. J Appl Pharm Sci 2011;3:5-8.

36. United State Pharmacopeia and National Formulary USP 40; The United States Pharmacopeial Convention, Inc: Rockville MD; 2017.

37. United State Pharmacopeia and National Formulary USP 30-NF 25; The United States Pharmacopeial Convention, Inc: Rockville MD; 2007.

38. Moore J, Flanner H. Mathematical comparison of dissolution profiles. Pharmaceutical Technol 1996;20:64-74.

39. Food and Drug Administration. Guidance for Industry: Dissolution Testing of Immediate-Release Solid Oral Dosage Forms; 1997.

40. Khan K, Rhodes CT. Effect of compaction pressure on the dissolution efficiency of some direct compression systems. Pharm Acta Helv 1972;47:594-607.

41. Anderson N, Bauer M, Boussac N, Khan Malek R, Munden P, Sardaro M. An evaluation of fit factors and dissolution efficiency for the comparison of in vitro dissolution profiles. J Pharm Biomed Anal 1998;17:811-22.

42. Hamdan II, Jaber AKB. Pharmaceutical evaluation of metformin $\mathrm{HCl}$ products available in the Jordanian market. Jordan J Pharm Sci 2010;3:1-6.

43. Hurtado y de la Peña M, Alvarado YV, Miriam Domínguez Ramírez A, Rosa Cortes Arroyo A. Comparison of dissolution profiles for albendazole tablets using USP apparatus 2 and 4 . Drug Dev Ind Pharm 2003;29:777-84.

44. Crison JR, Timmins P, Keung A, Upreti VV, Boulton DW, Scheer BJ. Biowaiver approach for biopharmaceutics classification system class 3 compound metformin hydrochloride using in silico modeling. J Pharm Sci 2012;101:1773-82.

45. Emara LH, Taha NF, El-Ashmawy AA, Raslan HM, Mursi NM. A rapid and sensitive bioanalytical HPLC method for determining diclofenac sodium in human plasma for bioequivalence studies. J Liq Chromatogr Relat Technol 2012;35:2203-16.

46. Medina JR, Salazar DK, Hurtado M, Cortes AR, Dominguez Ramirez, Miriam A. Comparative in vitro dissolution study of carbamazepine immediate-release products using the USP paddles method and the flow-through cell system. Saudi Pharm J 2014;22:141-7.

47. Medina JR, Aguilar E, Haurtado M. Dissolution behavior of carbamazepine suspensions using the usp dissolution apparatus 2 and the flow-through cell method with simulated GI fluids. Int J Pharm Pharm Sci 2017;9:111-6.

48. Langenbucher F, Benz D, Kurth W, Moller H, Otz M. Standardized flow-cell method as an alternative to existing pharmacopoeial dissolution testing. Pharm Ind 1989;51:1276-81.

49. McCarthy LG, Kosiol C, Healy AM, Bradley G, Sexton JC, Corrigan OI. Simulating the hydrodynamic conditions in the United States Pharmacopeia paddle dissolution apparatus. AAPS PharmSciTech 2003;4:83-98.

50. Kukura J, Baxter J, Muzzio F. Shear distribution and variability in the USP apparatus 2 under turbulent conditions. Int J Pharm 2004;279:9-17.

51. Gite S, Chogale M, Patravale V. Development and validation of a discriminating dissolution method for atorvastatin delayedrelease nanoparticles using a flow-through cell: a comparative study using USP apparatus 4 and 1 . Dissolution Technol 2016;23:14-20.

52. Sheorey SD, Hinge MA, Sengupta R, Menon BV. Pharmaceutical equivalence between different brands of Metformin Hydrochloride tablets. J Pharm Res 2012;5:3456-9.

53. Block L, Schemling L, Couto A, Mourao S, Bresolin T. Pharmaceutical equivalence of metformin tablets with various binders. J Appl Pharm Sci 2008;29:29-35.

54. Berthelsen R, Holm R, Jacobsen J, Kristensen J, Abrahamsson B, Müllertz A. Dissolution model development: formulation effects and filter complications. Dissolution Technol 2016;23:6-12.

55. Shaw SJ, Krauss GL. Generic antiepileptic drugs. Curr Treat Options Neurol 2008;10:260-8. 